\title{
Classifications of runoff and sediment data to improve the rating curve method
}

\author{
Hossein Khaledian, Homayoun Faghih, Ata Amini \\ Kurdistan Agricultural and Natural Resources Research and Education Centre, AREO, Sanandaj, Iran
}

\begin{abstract}
In this study, data classification method was evaluated to increase accuracy of estimating suspended sediment load. To achieve this objective, suspended sediment in Chehelgazi and Khalife Tarkhan rivers in Kurdistan, Iran, were estimated using sediment rating curve (SRC) method in three different approaches of data classification. At first, measured data were modelled without classification. Then, data based on flow statues were divided into two series as high and low flow. Eventually, based on sediment concentration, the data were divided into low and high sediment concentration. Long-term runoff and sediment data were used to calibrate rating curve model. The estimated values were compared with recorded data and the performances of these models were evaluated using statistical criteria. The results indicated an effective role of data classification to improve estimating sediment transportation by rating curve method. In one of the stations, it was observed that due to classification based on river flow and sediment concentration, model efficiency was increased about $45 \%$ and $28 \%$, respectively. Furthermore, in case of improving efficiency of SRC method, classifying data based on flow statues was found to be more effective than sediment concentration. The results of this study can be used to improve the management of the watershed by more accurately estimating the amount of suspended sediments transporting in the rivers draining to reservoirs.
\end{abstract}

Correspondence: Hossein Khaledian, Kurdistan Agricultural and Natural Resources Research and Education Center, AREO, Sanandaj, Iran.

Tel.: +98.9183734374.

E-mail: hkhaledian@yahoo.com

Key words: Modelling; river; sediment; rating curve method; watershed.

Received for publication: 27 November 2016.

Accepted for publication: 4 April 2017.

(C) Copyright H. Khaledian et al., 2017

Licensee PAGEPress, Italy

Journal of Agricultural Engineering 2017; XLVIII:641

doi:10.4081/jae.2017.641

This article is distributed under the terms of the Creative Commons Attribution Noncommercial License (by-nc 4.0) which permits any noncommercial use, distribution, and reproduction in any medium, provided the original author(s) and source are credited.

\section{Introduction}

Prediction of sediment is essential for river engineering projects and watershed management. Given the circumstances of watersheds and the state of registered data, a variety of hydraulic and hydrologic methods have been offered to estimate suspended sediment load of rivers. In many of Iran's hydrometric stations, there are no longterm sediments data and the available data has been recorded as flow and sediment magnitudes. In such circumstances, the use of methods based on direct measurement and statistical analysis have been considered, including sediment rating curve (SRC) (Heng and Suetsugi, 2015). SRC, using regression analysis and as a power equation, relates the water flow to the amount of suspended sediment. Regarding estimating the annual sediment, rating curves was used by many researchers. Morehead et al. (2003) stated that changes in sediment transport load in the rivers are affected by the variations in the flow than by any other factors. Wheat-Croft et al. (1997), to determine the annual sediment and factors affecting sediment yield in 46 hydrometric stations located in Ohio, established regression equations between the rating curves and factors such as the slope and watershed area. The results of this study indicated the effect of examined factors on sediment production. Achite and Ouillon (2007) indicated that the regression equations estimated the predicted values by $20 \%$ to $25 \%$ higher than the actual values. Also, the greatest amounts of sediment belong to autumn and spring respectively. They suggested that climate change must be considered in sediment load estimation studies. Amini et al. (2009) showed that climate and human changes of watersheds lead to increased runoff and frequent flood. Consequently, the suspended sediment concentrations increase in such area. Harrington and Harrington (2013) using the SRC at stations with inadequate data, in a few watersheds with monthly, daily, hourly and minute bases data of runoff, in Ireland, assessed the rating curve through logarithmic and power functions. They found out that using daily or monthly data has not had a significant effect on the accuracy of the model. Juston et al. (2014) emphasised the need to isolate errors due to inaccuracy of SRC from the error caused by changes in hydrological conditions of river system. They reported that because of various factors such as urbanisation, agricultural development and watershed management, this issue has not been seriously of interest to researchers. Rose et al. (2015) put a lot of importance on the speed of particles moving at different sections of the river in estimating suspended load, and proposed a method for calculating the sediment velocity.

In Iran, using exponential equations to calculate the suspended sediment load in rivers has caught attention. Varvani and Khalighi (2007), to determine the error rate resulting from the application of sediment rating curves in estimating sediment load in GhareChai River, compared the estimated values of 10 types of SRC with observed data in rising and recession hydrograph limbs. They showed that in all cases the sediment rating curves, estimates were $40 \%$ to $80 \%$ lower than the actual amount. Dehghani et al. (2009) 
obtained the rating curves with different classifications methods include seasonal, monthly, classified discharge, same hydrological period, dry and wet seasons, and the type of flow for modelling the sediment in the Doogh River. Their results showed that among the classified categories, the classification based on dry and wet seasons for the river provides better results. Despite the high use of rating curve method, this method also has its weaknesses (Koch and Smillie, 1986). Application of this method in calculating the amount of sediment transport in flood conditions is associated with large errors (Javaheri et al., 2006). In rivers, sediment concentration, for a certain amount of water in the raising hydrograph limb is more than that for the same estimated amount in recession limb. In other words, a non-linear relationship is struck up between runoff and sediment; however, the rating curve cannot model this non-linearity (Kisi and Karahan, 2006). Moreover, the use of this method requires continuous measurement, which is usually only possible for major and permanent rivers. The implementation of this approach has always been associated with large errors (Asselman, 2000).

The conducted studies indicated widespread application of the method of SRC in estimating sediment in watersheds. Whereas regression methods and SRCs are not enough to model the complexities of the relationship between discharge and sediment, and this method is inaccurate for using in various watersheds. Therefore, researchers modified this method with different techniques for unlike watersheds. In this research SRC, in two main sub-watersheds of the Gheshlagh watershed, was obtained at the stations located at the estuary of rivers flow into the Gheshlagh Dam reservoir in the city of Sanandaj. Furthermore, to accurate these curves, data classification was analysed based on classification of flow condition and sediment concentration. Then the efficiency of obtained rating curves in increasing the accuracy of estimation of suspended sediment load was assessed. Given the importance of the Gheshlagh Dam in supplying drinking water and the need to maintain the existing capacity of the dam, the results of this research can be used to achieving better management of Gheshlagh watershed to reduce incoming sedimentation.

\section{Materials and methods}

\section{Study area}

Gheshlagh watershed is located in the north of the Sanandaj, Kurdistan, Iran. The area of this watershed is $1070 \mathrm{~km}^{2}$, about $3.8 \%$ of the province. Gheshlagh Dam watershed has 2 main subwatersheds called Chehelgazi (parcel A) and Khalife Tarkhan. Khalife Tarkhan watershed also has 2 main sub-watersheds. In the comprehensive studies conducted on Gheshlagh watershed, they were named B and C parcels. The areas of these sub-watersheds are $267 \mathrm{~km}^{2}, 416.1 \mathrm{~km}^{2}$ and $386.9 \mathrm{~km}^{2}$, respectively. Gheshlagh Dam was constructed on the Gheshlagh River from the main tributaries of the Sirvan River and $13 \mathrm{~km}$ from the Sanandaj, in order to supply the drinking water of Sanandaj and irrigate 3000 ha of agricultural land. Dam's importance has resulted in regularly conducting studies and systematic sampling in the watersheds (Amini et al., 2014, 2017). Gheshlagh watershed runoff flows into Gheshlagh Dam reservoir through two main rivers of Chehelgazi and Khalife Tarkhan. At the estuary of these rivers into Gheshlagh Dam reservoir, there are two hydrometric stations named Chehelgazi (Station 1) and Khalifeh Tarkhan (Station 2) whose data were used in this study. The studied area and the location of these stations are shown in Figure 1.

\section{Runoff and sediment data}

In this study, the available data in Stations 1 and 2, which have been recorded by the Kurdistan Regional Water Authority (KRWA), were used. In these stations, respectively 363 (33 years) and 250 (26 years) corresponding data on runoff and sediment have been recorded. These data include the instantaneous discharge in $\mathrm{m}^{3} \mathrm{~s}^{-1}$ and sediment in tonday ${ }^{-1}$, which were measured simultaneously. Using Grubbs-Beck test (Grubbs and Beck, 1972), disparate data in both stations were identified. In this method, the upper and lower range of data were calculate using mean, standard deviation and Grubbs-Beck parameter and the data were associated with them. The data less than lower range and more than upper range were omitted (Faghih et al., 2015). In Stations 1 and 2, respectively, 3 and 1 disparate data were distinguished and omitted. Therefore, in this research, 360 and 249 desired samples of the discharge and sediment at Stations 1 and 2 were used, respectively. The scope and characteristics of runoff and sediment data are presented in Table 1.

Data homogeneity at hydrometric stations was analysed by Run Test (Bradley, 1968) through SPSS software. The results of this test for the measured data on runoff and sediment in both stations indicated the heterogeneity of the data. Heterogeneity of runoff and sediment data in watershed of Gheshlagh Dam, like many other watersheds, is because of different origins of the floods, land use changes, watershed management operations and manmade construction during the inventory period.

\section{Sediment rating curve}

One of the most common methods applied in assessing sediment load in rivers is SRC. The general form of SRC equation is as follows:

$$
\mathrm{Q}_{\mathrm{S}}=\mathrm{a} \times \mathrm{Q}_{\mathrm{W}}^{\mathrm{b}}
$$

where $\mathrm{Q}_{\mathrm{s}}$ is the rate of the suspended load (tonday ${ }^{-1}$ ), $\mathrm{Q}_{\mathrm{w}}$ is flow discharge $\left(\mathrm{m}^{3} \mathrm{~s}^{-1}\right)$ and $\mathrm{a}$ and $\mathrm{b}$ are constant coefficients. By determining the points on logarithmic coordinates, whose horizontal

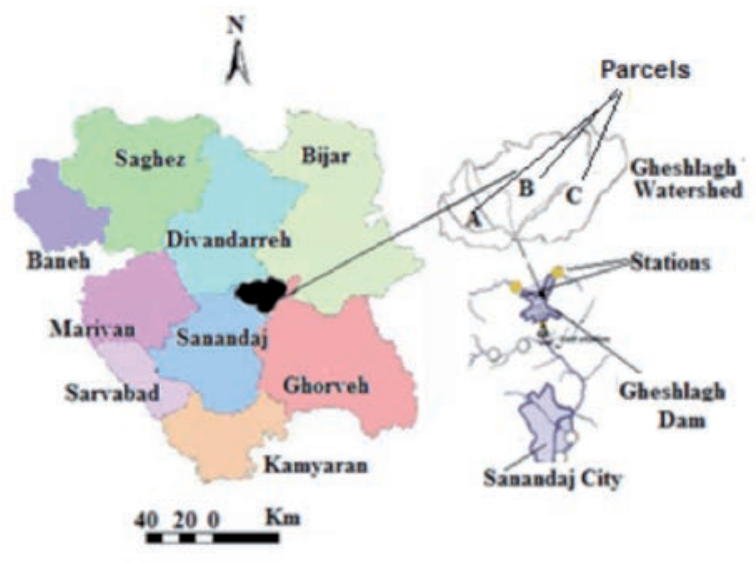

Figure 1. The studied area and the location of stations. 
Table 1. The range of corresponding data on runoff and sediment in study period.

\begin{tabular}{lcccc} 
Parameters & $\begin{array}{c}\text { Discharge } \\
\left(\mathrm{m}^{3} \mathrm{~s}^{-1}\right)\end{array}$ & $\begin{array}{c}\text { Sedation 1 } \\
(\text { tonday }\end{array}$ & $\begin{array}{c}\text { Discharge } \\
\left(\mathrm{m}^{3} \mathrm{~s}^{-1}\right)\end{array}$ & $\begin{array}{c}\text { Station } 2 \\
\text { Sediment } \\
(\text { tonday }\end{array}$ \\
Maximum & 40.521 & 15509.494 & 104.500 & 40373.498 \\
Minimum & 0.020 & 0.028 & 0.040 & 0.026 \\
\hline Median & 1.645 & 6.482 & 1.680 & 6.273 \\
Mean & 2.977 & 179.823 & 5.112 & 514.538 \\
\hline Standard deviation & 4.293 & 1052.615 & 9.928 & 3362.043 \\
\hline
\end{tabular}

and vertical axes are the flow and the sediment discharge respectively and by fitting the best line of these points, the sediment rating equation is obtained. In this study, the constant coefficients of Eq. (1) were calculated for the studied watershed in different modes.

\section{Data classification}

In order to study the effect of classifying data in increasing the accuracy of sediment transport caused by changes in river discharge, SRC was obtained in three different modes. In the first mode, runoff and sediment data were used without any classification in order to obtain the SRC (Mode A). In the second mode, based on the amount of runoff (Mode B) and in the third mode, based on the amount of sediment transport (mode C) runoff and sediment data were classified and their SRC were obtained. For this purpose, the corresponding data on the flow and sediment at the studied stations were inserted, in the format of columns, into MS-Excel spreadsheet. Then to derive appropriate equations for SRC curves, sediment and flow data were used as dependent and independent values for the model respectively.

\section{Based on flow discharge}

In this type of classification, based on the average daily of the river discharge (Model B), runoff data were classified into two sub-divisions of high $(\mathrm{BH})$ and low discharge (BL). For more information on the ranges and possibilities of classifying the recorded data, flow duration curves at Stations 1 and 2 were drawn. The flow duration curves at Stations 1 and 2 for the water year 1983-1984, as a sample, is shown in Figure 2. Flow characteristics of the studied rivers which are obtained from flow duration curves are shown in Table 2. The data in Table 2 shows that the average daily flow at Stations 1 and 2 are $1.543 \mathrm{~m}^{3} \mathrm{~s}^{-1}$ and $2.642 \mathrm{~m}^{3} \mathrm{~s}^{-1}$ respectively. These values (obtained from mean of long-term daily records) are different from the average values of the corresponding data of flow and sediment rate (Table 1). The flow having a discharge bigger than the average daily flow was classified as $\mathrm{BH}$, and vice versa was classified as BL. Data analysis showed that at Station 1, 185 data were in BH condition, while 175 data were in BL condition. These numbers for Stations 2 were 105 and 144, respectively.

\section{Based on sediment concentration}

In this method of data classification, the obtained average rate of sediment was used as the basis for classification of data (Model C). Based on the measured data, the average daily sediment at Stations 1 and 2, were calculated as 200 and $240 \mathrm{mg} \mathrm{L}^{-1}$ respectively and they were used in data classification. The flow having sediment concentration higher than the daily average was put in
Table 2. The specifications of recorded runoffs at the studied stations.

\begin{tabular}{cccccc} 
Stations & \multicolumn{5}{c}{ Flow discharge $\left(\mathrm{m}^{3} \mathrm{~s}^{-1}\right)$} \\
& Low water & High water & Normal & Average & Median \\
1 & 0.054 & 1.794 & 0.618 & 1.543 & 0.616 \\
2 & 0.186 & 2.904 & 1.094 & 2.642 & 1.089 \\
\hline
\end{tabular}

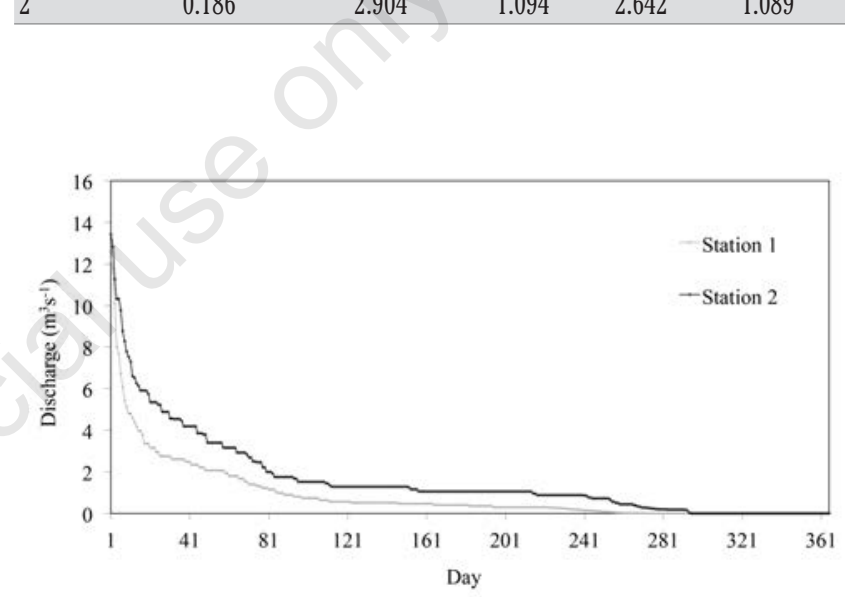

Figure 2. Flow duration curves in 1983-1984 water year.

high concentration $(\mathrm{CH})$, and the flow having sediment concentration less than the daily average was put in low concentration (CL). From data recorded in the Station 1, 65 data were classified as $\mathrm{CH}$ and 295 data were classified as CL. For Station 2, these numbers were 32 and 217, respectively.

\section{Calibration and validation}

For each of the three models, the randomly picking rows (data corresponding runoff and sediment) were conducted in a MSExcel spreadsheet. Then $70 \%$ of each paired data were used for training (calibration) and 30\% for testing (validation) the models. This categorisation of data in modelling is used for obtaining the SRC (Vali et al., 2010; Abdelwahab et al., 2013). In this study, in order to verify the models, by using MS-Excel spreadsheet, the exponential relationships between the corresponding data of flow and sediment (training data) were obtained. Then validations of models were performed by comparing the results of developed models with recorded data. To ensure the process of modelling, validation and evaluation of the accuracy of the developed models, and comparing models in various states, the statistical criteria of root mean square error (RMSE) and mean absolute error (MAE) 
were used. These criteria evaluate the precision of model based on the difference between actual and estimated values. RMSE and MAE are obtained from Eqs. (2) and (3), respectively. RMSE and MAE values range from zero to infinity. The closer RMSE and MAE values are to zero, the better performance of the model is:

RMSE $=\sqrt{\frac{\sum_{\mathrm{i}=1}^{\mathrm{n}}\left(\left(\mathrm{y}_{\text {est }}\right)_{\mathrm{i}}-\left(\mathrm{y}_{\text {obs }}\right)_{\mathrm{i}}\right)^{2}}{\mathrm{n}}}$

$$
\operatorname{MAE}=\frac{\sum_{\mathrm{i}=1}^{\mathrm{n}}\left|\left(\mathrm{y}_{\text {est }}\right)_{\mathrm{i}}-\left(\mathrm{y}_{\text {obs }}\right)_{\mathrm{i}}\right|}{\mathrm{n}}
$$

where yobs is observed values, yest is the estimated values (output) and $\mathrm{n}$ is the number of data.

\section{Results and discussion}

The analysis conducted on flow duration curve and sediment data, indicated that the average daily flow for the Stations 1 and 2 were $2.642 \mathrm{~m}^{3} \mathrm{~s}^{-1}$ and $1.543 \mathrm{~m}^{3} \mathrm{~s}^{-1}$. The average daily load for Stations 1 and 2 was estimated as 26.66 tonday $^{-1}$ and 54.78 tonday $^{-1}$ respectively. Considering the area of Chehelgazi and Khalifeh Tarkhan watersheds, the erosion rates of suspended sediment load were 36.4 tonyr $^{-1} \mathrm{ha}^{-1}$ and 25 tonyr $^{-1} \mathrm{ha}^{-1}$, respectively. In this study, runoff and sediment data were used to obtain the SRC. For calibration of the models, the exponential relationships were obtained between the corresponding data of flow and sediment discharge for training data. In both stations, according to the mentioned categories, five different SRCs, in various states, including a SRC with no classification (A), two SRCs with classi- fication based on the flow (BH and BL) and two SRCs with classification based on sediment concentration $(\mathrm{CL}$ and $\mathrm{CH})$ were drawn and their relations obtained. These SRCs and their relationships are shown in Figure 3.

The results showed that most of the total suspended sediment were transported during the high flow regime $(\mathrm{BH})$ while under low flow conditions (BL) the sediment transportation were slighter. These findings are consistent with (De Girolamo et al., 2015). In order to quantify the accuracy of the models, statistical analysis for test data in Stations 1 and 2 are presented in Table 3. Table 3 also shows the number of training and testing data in each of the obtained models. To evaluate and compare the results of models with various mods of classification, training and testing data that were used in $\mathrm{BL}$ and $\mathrm{BH}$ models, were compared with the actual data and the results are presented as Model B. Similarly, CH and CL models were verified. In Table 3 Model B and C represented the models achieved with entire data. Totally, they are corresponding to training and testing data of Model A.

The results from Table 3 showed that in terms of the training data, at Station 1, RMSE for Models B and C were as $37.8 \%$ and $20 \%$ less than the Model A, respectively. These amounts were as $64.3 \%$ and $33.2 \%$ at Station 2. In terms of the testing data, RMSE for Models B and C were 25\% and 20\% less than the Model A respectively at Station 1 and $25 \%$ and $21 \%$ at Station 2 . For total data (training and testing), at Station 1, RMSE for Models B and C were $35 \%$ and $20 \%$ less than Model A respectively. At Station 2 these values were as $45 \%$ and $28 \%$. The values of statistical criteria in Table 3 showed that in both stations, applying data classification has led to an increase in the accuracy of data prediction compared to the non-classified modes. Table 3 also showed that the classification based on flow discharge was more effective than sediment concentration. Thus, the order of models efficiency was as $\mathrm{B}, \mathrm{C}$ and $\mathrm{A}$. The amount of reduction in the estimated error for Model B, compared to C and A at Station 1, was 19\% and 35\% respectively. At Station 2, there were $24 \%$ and $45 \%$ respectively. Moreover, in the case of low discharge (BL) the accuracy of the model was higher than that in high flow mode $(\mathrm{BH})$. These findings indicate that major part of the errors in estimating sediment is

Table 3. The summary of the statistical results of comparison of the SRC models efficiency.

\begin{tabular}{|c|c|c|c|c|c|c|c|c|c|c|c|}
\hline \multirow[t]{2}{*}{ Model data } & & \multirow{2}{*}{$\begin{array}{c}\text { The number } \\
\text { of data }\end{array}$} & \multicolumn{4}{|c|}{ Station 1 (tonday $\left.^{-1}\right)$} & \multirow{2}{*}{$\begin{array}{c}\text { The number } \\
\text { of data }\end{array}$} & \multicolumn{3}{|c|}{ Station $2\left(\right.$ tonday $\left.^{-1}\right)$} & \multirow[b]{2}{*}{ MAE } \\
\hline & & & Mean & St.dev. & RMSE & MAE & & Mean & St.dev. & RMSÉ & \\
\hline \multirow[t]{3}{*}{ A } & Training & 252 & 192 & 1134 & 1027 & 160 & 174 & 476 & 3183 & 2919 & 427 \\
\hline & Testing & 108 & 151 & 836 & 761 & 126 & 75 & 604 & 3766 & 3584 & 545 \\
\hline & Total & 360 & 180 & 1053 & 955 & 150 & 249 & 514 & 3362 & 3134 & 462 \\
\hline \multirow[t]{2}{*}{$\mathrm{BH}$} & Training & 129 & 385 & 1570 & 892 & 242 & 73 & 1121 & 4860 & 1608 & 613 \\
\hline & Testing & 56 & 260 & 1137 & 796 & 199 & 32 & 1409 & 5717 & 4107 & 993 \\
\hline \multirow[t]{2}{*}{ BL } & Training & 123 & 3.13 & 5.15 & 5 & 2.3 & 101 & 9.89 & 59.0 & 59 & 9 \\
\hline & Testing & 52 & 3.17 & 4.44 & 4 & 2.2 & 43 & 4.43 & 5.61 & 5 & 3 \\
\hline \multirow[t]{3}{*}{ B } & Training & 252 & 192 & 1134 & 639 & 125 & 174 & 476 & 3183 & 1043 & 262 \\
\hline & Testing & 108 & 151 & 836 & 571 & 103 & 75 & 604 & 3766 & 2682 & 425 \\
\hline & Total & 360 & 180 & 1053 & 620 & 119 & 249 & 514 & 3362 & 1711 & 311 \\
\hline \multirow[t]{2}{*}{$\mathrm{CH}$} & Training & 46 & 1001 & 2521 & 1387 & 292 & 22 & 3626 & 8459 & 4040 & 876 \\
\hline & Testing & 19 & 806 & 1897 & 1025 & 227 & 10 & 4433 & 9888 & 5098 & 1106 \\
\hline \multirow[t]{2}{*}{ CL } & Training & 206 & 11.6 & 22.3 & 1 & 0.8 & 152 & 20.1 & 48.1 & 1.7 & 1.1 \\
\hline & Testing & 89 & 10.8 & 19.7 & 1.3 & 1 & 65 & 14.6 & 28.2 & 2 & 1.6 \\
\hline \multirow[t]{3}{*}{$\mathrm{C}$} & Training & 252 & 192 & 1134 & 822 & 117 & 174 & 476 & 3183 & 1949 & 285 \\
\hline & Testing & 108 & 151 & 836 & 608 & 100 & 75 & 604 & 3766 & 2818 & 493 \\
\hline & Total & 360 & 180 & 1053 & 763 & 112 & 249 & 514 & 3362 & 2246 & 347 \\
\hline
\end{tabular}



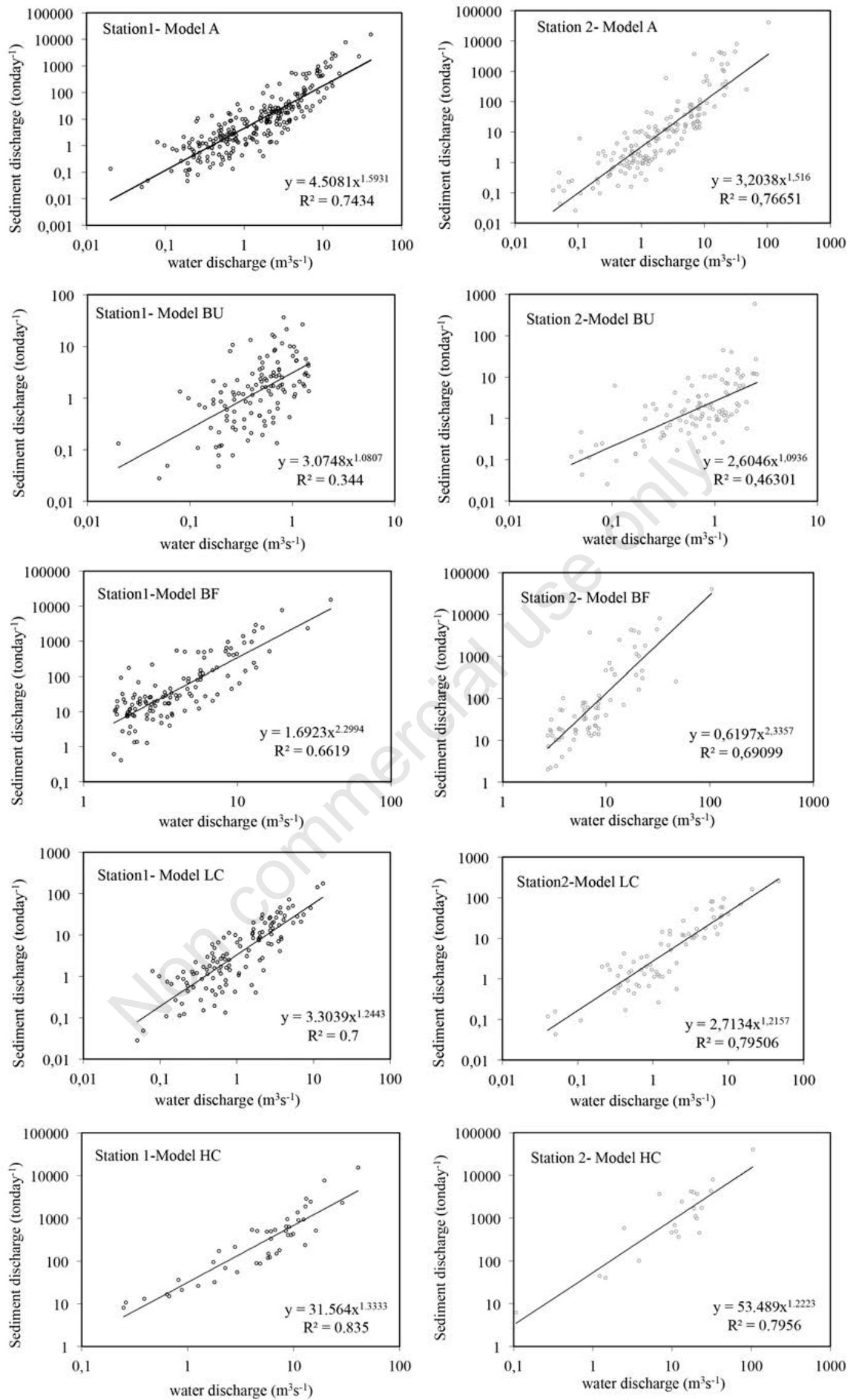

Figure 3. The sediment rating curve and corresponding equations in different modes of modelling. 
related to the flow data.

In Figure 4 the outcomes of the models in estimating the total data (training and testing) are shown for both stations. The disparate results obtained from SRC in current study is consistent with those of (Horowitz, 2003) who found that the SRC method tends to under predict and over predict. Figure 4 indicated that at both stations, Models B and $\mathrm{C}$ have a better fitness than Model A. Thus it can be concluded that the SRC using data division (modes B and C), was with a better ability to estimate sediment load in the Gheshlagh watershed and estimated data have proper fitness and are in good agreement with the actual data (particularly at Station 2). This finding is in agreement with the findings of Dehghani et al. (2009) and Jansson (1996) about the accuracy of the SRC in terms of data classification based on the low-flow and high flow sets.

\section{Conclusions}

In this study, the data of runoff and sediment from two stations at the estuary of Sanandaj Vahdat Dam were used to estimate the amount of sediment load entering the dam reservoir. Due to lack of data, and the way was recorded, and consequently the impossibility to use hydraulic methods based on the balance of sediments, SRC was chosen to predict suspended sediment load. Due to the fact that the highest amount of sediment occurs in flood periods, using this method to estimate sediment transport in flood conditions was associated with significant error. This method deals similarly with all points of observation including the discharge of both base flow and flood. Since the number of simultaneous data on flow and sediment discharge are far less during floods, rating curve is inclined towards lower values. Therefore, in this study in order
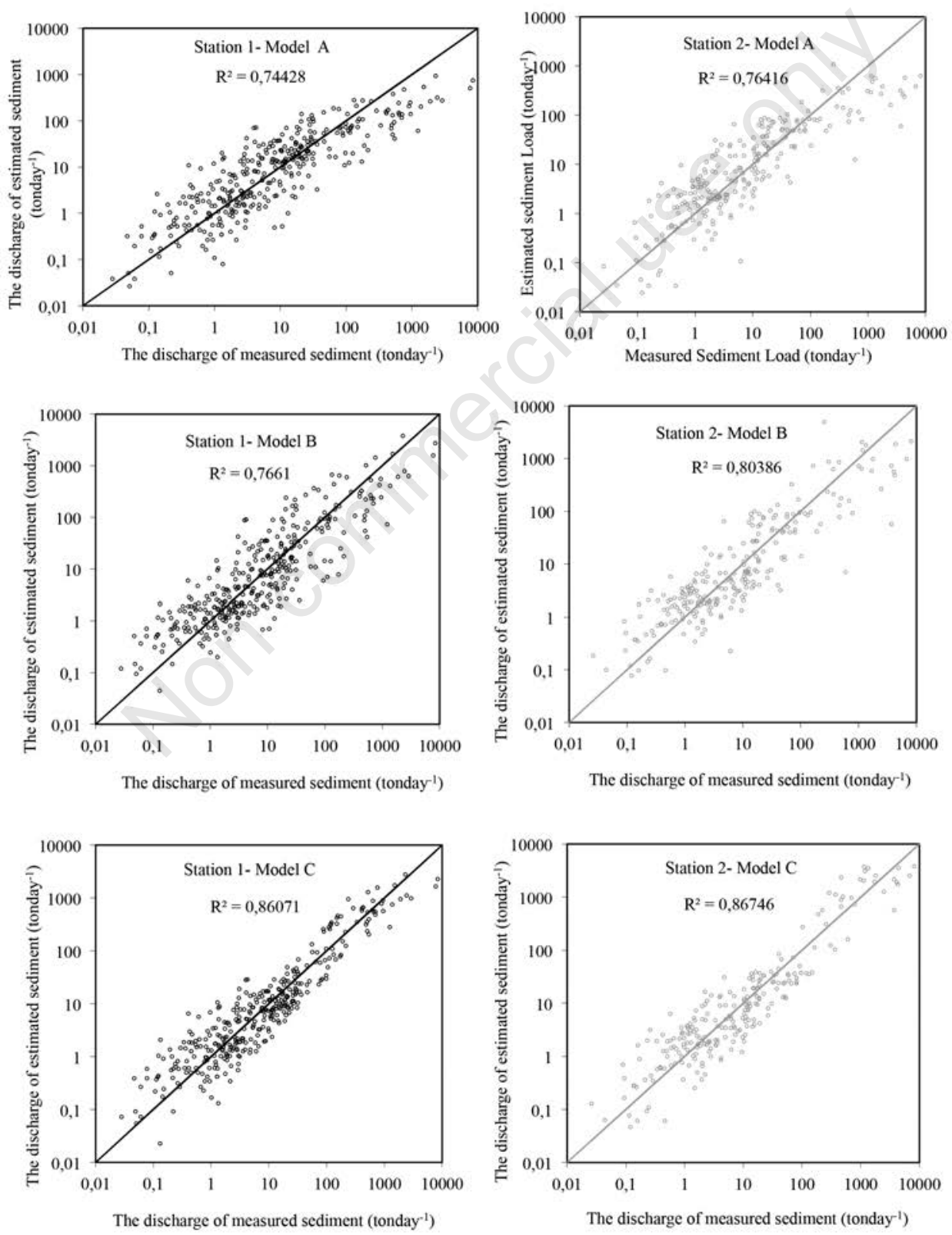

Figure 4. The efficiency of sediment rating curve obtained in different modes. 
to increase the accuracy of sediment load estimation, in addition to derivation SRC based on available data, data classification method was used. The data were classified on the basis of flow and sediment. The results showed that by using data classification, the error of SRC was reduced. So that the decrease in estimation error of Models B and C in proportion to Model A at Station 1, was 35\% and $20 \%$ and at Station 2 , it was $45 \%$ and $28 \%$ respectively. By comparing the model results, it was found that data classification based on the mean flow discharge (Model B) was with better performance and increased accuracy of the rating curve.

The results of this research can be applied to estimate the amount of suspended sediment load in the Gheshlagh River to predict trends in river morphology, and optimise the methods of protecting the dam reservoir. The absence of required data for hydraulic methods, uncertainty of some recorded data, the lack of data in some years of the period (statistical gap), lack of data releases by KRWA in recent years were the limitation of this study. Similar studies in combination with field measurements and using more up to date data could be of interest to other researchers.

\section{References}

Abdelwahab M.M.O., Bisantino T., Milillo F., Gentile F. 2013. Runoff and sediment yield modeling in a medium-size Mediterranean watershed. J. Agricult. Engine. XLIV(s2):e7, 31-40.

Achite M., Quillon M. 2007. Suspended sediment transport in a semiarid watershed, Wadi Abd, Algeria. J. Hydrol. 343:187-202.

Amini A., Arya A., Eghbalzadeh A., Javan M. 2017. Peak flood estimation under overtopping and piping conditions at Vahdat Dam, Kurdistan Iran. Arabian J. Geosci. [Epub ahead of print].

Amini A., Taheri P., Javan M., Saghafian B. 2014. Evaluating the impacts of watershed management on runoff storage and peak flow in Gav-Darreh Watershed, Kurdistan, Iran. Arabian J. Geosci. 7:3271-9.

Amini A., Thamer M. A., Ghazali H., Huat B. 2009. Adjustment of peak stream flows of a tropical river for urbanization. Am. J. Environ. Sci. 5:285-94.

Asselman N. 2000. Fitting and interpretation of sediment rating curves. J. Hydrol. 234:228-48.

Bradley J.V. 1968. Distribution-free statistical tests. Prentice Hall, Englewood Cliffs, NJ, USA.

Dehghani A.A., Zanganeh M.E., Mosaedi A., Kouhestani N. 2009. Comparison of suspended sediment estimation by artificial neural network and sediment rating curve methods (case study: Doogh River in Golestan province). J. Agric. Sci. Nat. Resour. 16:266-76.

De Girolamo A.M., Pappagallo G., Lo Porto A. 2015. Temporal variability of suspended sediment transport and rating curves in a Mediterranean river basin: The Celone (SE Italy). Catena
$128 ; 135-43$.

Faghih H., Amini A., Haidari F., Khalili K. 2015. Assessing the Artificial Neural Network efficiency to estimate suspended sediment load using classified data. J. Environ. Water Eng. 1:51-64.

Grubbs F.E., Beck G. 1972. Extension of sample sizes and percentage points for significance tests of outlying observations. Technometrics 14:847-54.

Harrington S.T., Harrington J.R. 2013. An assessment of the suspended sediment rating curve approach for load estimation on the rivers Bandon and Owenabue, Ireland. Geomorphology 185:27-38.

Heng S., Suetsugi T. 2015. Regionalization of sediment rating curve for sediment yield prediction in ungauged catchments. Hydrol. Res. 46:2-38.

Horowitz A.J. 2003. An evaluation of sediment rating curves for estimating suspended sediment concentrations for subsequent flux calculations. Hydrol. Process. 17:3387-409.

Javaheri N.A., Ghomeshi M., Kashefipour S.M. 2006. Comparison of statistical regression and fuzzy methods for estimating sediment load for Karoon and Dez Rivers. Sci. J. Agricult. 28:183-200.

Jansson M.B. 1996. Estimating a sediment rating curve of the Reventazón river at Palomo using logged mean loads within discharge classes. J. Hydrology 183;227-41.

Juston J., Jansson P.E., Gustafsson D. 2014. Rating curve uncertainty and change detection in discharge time series: case study with 44-Year historic data from the Nyangores River, Kenya. Hydrol. Process. 28;2509-23.

Kisi O., Karahan M.E. 2006. Sen. River suspended sediment modeling using a fuzzy logic approach. Hydrol. Process. 20:4351-62.

Koch R.W. Smillie G.M. 1986. Comment on "river loads underestimated by rating curves" by R.I. Ferguson. Water Resour. Res. 22:2121-22.

Morehead M.D., Syvitski J.P., Hutton E.W.H., Peckham S.D. 2003. Modeling of temporal variability in the flux of sediment from ungauged river basins. J. Global Planet. Change 39:95110.

Rose C.W., Shellberg J.G., Brooks A.P. 2015. Modelling suspended sediment concentration and load in a transport-limited alluvial gully in Northern Queensland, Australia. Earth Surf. Process. Landf. 38:1765-78.

Vali A.A., Moayeri M., Ramesht M.H., Movahedinia N. 2010. A comparative performance analysis of artificial neural networks and regression models for suspended sediment prediction (case study: Eskandari cachment in Zayande Roud basin, Iran). Phys. Geograp. Res. 42:21-30 [In Persian].

Varvani J., Khalighi Sh. 2007. Investigation of sediment rating curves error for estimating flood events sediment yield in Gharachay River. N. Find. Agricult. 1:201-14 [In Persian].

Wheat-Croft R.A., Sommerfield C.K., Drake D.E. 1997. Rapid and widespread dispersal of flood sediment on the northern California margin. Geology 25:163-6. 